\title{
Deer Who Are Distant
}

\section{Response Congruency to Relative Pronouns Across Human and Nonhuman Entities}

\author{
Denise Dillon \\ James Cook University, Singapore \\ denise.dillon@jcu.edu.au \\ Josephine Pang \\ James Cook University, Singapore, Townsville, Australia
}

\begin{abstract}
The study explores the influence of relative pronouns WHO or THAT on attributions of humanness across four categories of entities (unnamed nonhuman animals, named animals, machines, and people). Eighty-three university students performed an attribution task where they saw a priming phrase containing one category item with either wHO or тнAт (e.g., deer who are ...) and then two trait attribute items (Uniquely Human UH/ Human Nature HN word pairs; e.g., distant-nervous), from which they selected the trait attribute most meaningfully suited to the phrase. Data were analyzed with a repeated measures 2 (humanness: HN traits, UH traits) $\times 2$ (pronoun: WHO, THAT) $\times 4$ (category: unnamed animals, named animals, machines, people) ANOvA. Participants responded relatively faster to $\mathrm{HN}$ trait attributes than to $\mathrm{UH}$ traits, and responded faster to named animals than to all other entities. Faster responses also ensued for people-wHO pairings than people-THAT pairings, and vice versa for named animals.
\end{abstract}

\section{Keywords}

attributions of humanness - relative pronouns - language and behavior

The study of language processes is important because humans communicate with each other primarily via the written and spoken word. The influence of language on behavior can be subtle (e.g., Hart \& Albarracín, 2009), but should

(C) DENISE DILLON, 2017 | DOI 10.1163/15685306-12341482

This is an open access article distributed under the terms of the Creative Commons AttributionNoncommercial 4.0 Unported (CC-BY-NC 4.0) License. 
not be ignored. For example, language offers insight into people's mental health, and some therapies involving language are effective in improving mental health (Pennebaker, 2002). As for the specific choice of words we use for referent categories, Brown (1958), an eminent psychologist in the area of child language development, reminded us that "there is a sense in which lexicon determines cognition and inferences about cognition can be based on lexicon" (p. 245). Put simply, we can get a sense of how people are thinking through what they choose to say.

Importantly also, cognitive psychology research has shown that, when faced with a discrepancy between language and belief, people will change one or the other to reduce what is known as cognitive dissonance. In the context of animal advocacy, the choice to include nonhuman animals in the same category of living entities as humans is reflected in subtle language practices such as pronoun use (e.g., hens who suffer in egg factories) (Dunayer, 2001). Another such practice involves metaphors whereby nonhuman animal characteristics are used to infer derogatory evaluations of people (e.g., women who are perceived as overly protective are "clucky") by emphasizing their "animal" nature which is somehow perceived to be less than human (Dunayer, 2001). In recent years, psychological research interest has extended from the content of a message to the linguistic style of the message (e.g., Pennebaker \& King, 1999) — that is, how individuals phrase what they wish to say (Pennebaker, Mehl, \& Niederhoffer, 2003). Linguistic style is reflected, for example, in the way one uses function words (Pennebaker, 2002) including THE, MY, WHO, WHICH, and THAT.

\section{Function Words}

The class of function words is extremely important, as they give meaning and context to nouns, adjectives, and verbs (Chung \& Pennebaker, 2007). They are also some of the most commonly used words in the English language. Although people may pay little attention to function words, they can influence listeners or readers strongly, and provide insight into writers' and speakers' thoughts (Chung \& Pennebaker, 2007). Relative pronouns are examples of function words. Of particular interest in the current study are the relative pronouns WHO and THAT.

Cambridge Dictionaries Online (2016) says the relative pronoun тнAт is used "to introduce defining relative clauses. We can use that instead of who, whom or which to refer to people, animals and things. That is more informal than who or which." In comparison, the entry on wHO states this relative pronoun is used to refer to people "and sometimes to pet [sic] animals." This latter usage is all the more common (and probably expected) if an animal has an individualized 
name (e.g., Peter the parrot who loves his seeds, versus the wild parrot that ate the bird seed). Jacobs (2005) described the renowned scientist Jane Goodall's struggle to have her first scientific paper accepted in its original form, with chimpanzees referred to as he or she, and as who, whereas the journal editor wanted these amended to it and which, respectively. However, it seems the practice of using wHO to refer to nonhuman animals is becoming more commonly accepted. Anecdotal evidence also indicates that the word тнAт is frequently used when referring to humans (e.g., Students that study hard do well in their exams).

Gilquin and Jacobs (2006) examined the variance in the usage of the pronoun wHO with regard to nonhuman animals over the past 40 years. They compared grammar rules relating to the correct use of the pronoun wHO listed in 45 reputable sources and found that it could be acceptable to use WHO when speaking of nonhuman animals, although only in limited contexts. Some factors that helped determine when the use of wHO was appropriate included mention of the animal's gender, the writer's or speaker's attitude toward the animal, and whether the animal had a name (e.g., Fluffy the cat).

Regarding the use of тнАт, anecdotal evidence suggests the word is being used as a replacement for wHO when referring to humans. This may be because grammatically correct use of THAT is not restricted to a particular type of target; consider as examples extracts from news reports (e.g., "throngs [of people] that showed up," Hussain, 2010) and articles posted on reputable websites (e.g., "Children that are secondhand smokers could have extended sleep problems," 2009). In some instances, this may be a way for writers to distance either themselves or their audience from bad news.

Some examples include personal reflections of missing children (e.g., "a group of children that were not lucky enough to be sitting at home with their family," Barrett, 2009) and a news report concerning child murderers (e.g., "Robert Kinscherff, a clinical psychologist and senior associate at the us' National Centre for Mental Health and Juvenile Justice, said children that kill usually fall into one of three categories ..."; Brook, 2016). In referring to people as THAт, there could be an element of dehumanization through inclusion in a broader category that includes animals and things instead of the relatively narrower category that includes just people and companion animals. However, more research is required before a more conclusive statement can be made.

Other media, such as classic literary works, are further evidence that the use of тнAт as a human referent is pervasive and has been for some time. In The Catcher in the Rye (Salinger, 1984/1951), the protagonist Holden Caulfield consistently uses тнат to refer to people (e.g., "that lunatic ... that lived in tombs," p. 54). The narrator in The Scarlet Letter (Hawthorne, 1997/1850) also uses T HAT in several instances to refer to people; for example, in the introduction, he narrates about "some of the characters that move in [the house]" (p. 37). 
The phrasing of a sentence in the English language often has implications with regard to dehumanization or, conversely, to the attribution of humanness to nonhumans (e.g., Gupta, 2006). People often attribute humanness to nonhuman entities (anthropomorphism; Kwan \& Fiske, 2008; e.g., "my computer is being stubborn") and sometimes ascribe lesser humanness to other people (dehumanization; Haslam, 2006). The attribution of human traits to nonhuman entities can be used purposely for effect, especially in art and literature, as first noted by Ruskin (1856). Either through "willful fancy" or by "an excited state of feelings," the pathetic fallacy involves the attribution of the characteristics of a living creature to an inanimate entity. For example, a poet might write metaphorically about dancing leaves or of the cruel sea. Similarly, anthropomorphism is defined for scientific purposes (i.e., in Reber's 1985 Dictionary of Psychology) as "attributing human characteristics to lower organisms or inanimate objects" with the caution to be "careful not to imbue non-humans with what may be species-specific human characteristics" (p. 42).

In an example of dehumanizing language and thinking, Khanna (2008, p. 41) explores a human-based distancing effect through relatively current events in South Africa. She draws on Hannah Arendt's analogy whereby Arendt aligns refugees with dogs in their status as dehumanized individuals. In her chapter on the decline of the nation state, and writing about minorities and stateless people, Arendt (1951) argued that, as fame might improve a refugee's chances of rising through the social strata, so does a stray dog's chance of survival improve through the individuating act of naming.

Only fame will eventually answer the repeated complaint of refugees of all social strata that "nobody here knows who I am"; and it is true that the chances of the famous refugee are improved just as a dog with a name has a better chance to survive than a stray dog who is just a dog in general (p. 287).

However, Khanna noted suggestions that most police dogs in South Africa should be killed because they are "too psychologically sick to be rehabilitated" (p. 42). Further, as a consequence of a 1998 police-dog attack on illegal immigrants, the connotations of the expression "like a dog" came to be reconsidered such that the act of killing the police dogs involved in the attack on the immigrants could somehow serve as a remediation for human dignity by maintaining a distance between human and dog/animal. Khanna gives literary examples (including Kafka) through which we see that the notion to "die like a dog" is taken to mean death without rights or dignity. Khanna also uses an example from J. M. Coetzee's novel, Disgrace, as a contrast whereby "the only possibility for dogs like these [i.e., police dogs involved in acts of violence against humans] is for them to die with dignity or to be given the gift of death" (p. 42). In contrast, those killed by the police dogs are in the position of dehumanized individuals without recourse to either dignity or grace. 
Language use, in turn, may influence behavior (Carroll, 1956). Some research on sexist language supports this view. For instance, Brooks (1983) found that female eighth-grade students in a female-biased language condition rated Occupational Therapist lower on gender appropriateness than did male students. Chartrand, Fitzsimons, and Fitzsimons (2008) were of the opinion that attributing human traits to a nonhuman entity could result in a person unthinkingly reacting to the entity in a particular way. In their experimental study where participants were set up to think about (i.e., primed with) either dogs (loyal), cats (not loyal), or canaries (neutral), dog-primed participants scored higher on a loyalty questionnaire than did cat-primed or canary-primed participants. The effect was independent of participants' selfidentification as a dog/cat/bird person. In the preceding paragraphs, there is some support for the idea that language may influence attitudes to both dehumanization and attributions of humanness, and this, in turn, may affect behavior. Gupta (2006) documented examples wherein the pronoun wHO attributed human traits (sentience and personality) to nonhuman animals (foxes).

She investigated the use of wHO in foxhunting discourse published on the Internet and found (perhaps what some might consider as counterintuitive) that supporters of foxhunting tended to anthropomorphize foxes more than horses or hounds. Supporters seemingly described the fox in anthropomorphic terms as a worthy opponent so as to thereby boost their own status as successful hunters. Those who were pro-foxhunting were also more likely than those who were anti-foxhunting to use wHO as a referent to the fox. To explain this point, Gupta drew on Biber, Johansson, Leech, Conrad, and Finegan's reference work (1999, pp. 317-318, as cited in Gupta, p. 108) wherein he and she form types of "personal reference," while it is categorised as "nonpersonal." As Gupta herself quotes from Biber et al.: "Personal reference expresses greater familiarity or involvement. Non-personal reference is more detached" (p. 108).

She goes on to note that fox-hunting behavior in itself fosters familiarity with foxes through observation of their habits and habitat, and it is perhaps this greater familiarity with foxes that promotes at the same time affection for them. Further, Gupta argues that the greater the attribution of sentience to the fox as prey, the greater the creature's worth as an opponent for the hunter. Sentience is often ascribed more strongly to humans than to nonhuman animals, so humanized attributions to a prey, such as bravery and cunning, increase the esteem of a successful hunter. Says Gupta, "personalizing an animal does not preclude hunting the animal and is not necessary for its defence" (p. 119). It also appears that even within the people category there are degrees of perceived humanness. 


\section{Humanness and Dehumanization}

In a series of experimental studies, Haslam and his colleagues (Haslam, 2006; Haslam \& Bain, 2007; Haslam, Bain, Douge, Lee, \& Bastian, 2005) reported evidence for the notion that attributions to humanness range on a continuum from traits believed to be uniquely human (UH) (e.g., moral sensibility) to traits believed to be part of typical human nature $(\mathrm{HN})$ (e.g., interpersonal warmth). Although the former may be unique to humans, not every person has all of these traits; UH traits develop over time and differ from culture to culture, while, in contrast, HN traits are thought to be innate (Haslam, 2006). In addition, although humans share HN traits with other animals, these traits are viewed as an essential part of being human (Haslam, 2006).

Given the evidence for these two types of human attributes, and that dehumanization is defined as the denial of humanness to a target, it stands to reason that there are two corresponding forms of dehumanization. Haslam (2006) identifies these as (a) animalistic dehumanization, where $\mathrm{UH}$ traits are denied to a target, likening the target to a nonhuman animal, and (b) mechanistic dehumanization, where $\mathrm{HN}$ traits are denied to a target, likening the target to a robot or some other machine. As an outcome of his review of "manifestations and theories of dehumanization," Haslam proposed that dehumanization is not extraordinary or exercised only in extremity. Instead:

An expanded sense of dehumanization emerges, in which the phenomenon is not unitary, is not restricted to the intergroup context, and does not occur only under conditions of conflict or extreme negative evaluation. Instead, dehumanization becomes an everyday social phenomenon, rooted in ordinary social-cognitive processes. (p. 252)

In the obverse, Gupta's finding that fox hunters tended to humanize the fox is an example of another social phenomenon whereby, to paraphrase Loughnan and Haslam, humanization need not occur only under conditions of harmony or extreme positive evaluation. Loughnan and Haslam (2007) found some support for the idea that the two types of dehumanization exist. They discovered that artists and nonhuman animals were implicitly associated with HN traits, whereas businesspeople and automata ${ }^{1}$ were implicitly associated with $\mathrm{UH}_{\mathrm{H}}$ traits. However, their study aims did not extend to exploring whether social cognitive processes influence the humanization of animals.

1 Automata in this sense refers to a moving mechanical device that replicates some form/s of human function. 
The current study builds upon Loughnan and Haslam (2007) in that it examines attributions of humanness to four types of nonhuman and human entities. However, instead of social categories of people (i.e., artists, businesspeople), the focus remains on humans and nonhumans, while nonhuman entities are extended to include named animals in addition to unnamed animals and automata as employed in Loughnan and Haslam. The four types of entities are thus unnamed animals ${ }^{2}$, named animals, machines, and people. An additional element in the present study involves the influence of the relative pronouns WHO and THAT on attributions of humanness to entities in the four categories, which is a foray into a relatively new area of research.

As such, the main hypothesis of the current study states that attributions of humanness to entities in four categories - animal, named animal, machine, and people - would be influenced by the use of either wHO or THAT in a priming phrase (e.g., [priming phrase] Deer who are / [humanness trait pair HN-UH] NERVOUS-DistANT). McNamara (2005) defined priming as, "an improvement in performance in a perceptual or cognitive task, relative to an appropriate baseline, produced by context or prior experience" (p. 3). Among other common findings in priming tasks, McNamara explained that a response congruency effect comes from an incongruence between primes and targets that vary on meaning dimensions such that only when a meaning is congruent to the target is there unconscious activation (hence faster response times). In the context of the current study, the priming phrase includes an entity plus a pronoun that arguably most strongly indicates either a being (WHO) or a thing (тнAт). The target here is the humanness trait attribution which, according to Haslam and his colleagues, extends along a continuum of humanness and can indicate dehumanization towards the status of nonhuman animal or, at the other end of the continuum, towards the status of nonliving entities such as machines.

\section{Materials and Methods}

\section{Materials}

Category Items

A pilot study was conducted to ascertain if entities allocated to four categories were representative. The four types of entities were animal, machine, named animal, and people. For the animal and named animal entities, words that carried strong metaphorical human connotations (e.g., SHARK) were, as much as possible, excluded.

2 For the purposes of brevity, the category of "unnamed animals" is from here-on-in referred to as "animals." 
Data regarding the lexical characteristics (e.g., word frequency, word length) of 80 word items representing the four types of entities-2o per categorywere obtained from the English Lexicon Project ${ }^{3}$ (ELP, Balota et al., 2007) website from which researchers can gain such information. Their lexical characteristic data has been collated from thousands of studies using word and nonword stimuli. Due to the nature of language, word frequency distributions are inherently skewed (a small group of high-frequency words and many lowfrequency words leads to positive skewness), so a log transformation was used on the raw frequency data to reduce skewness (Zipf, 1935). A single-factor ANOVA revealed that the 80 words were similarly matched on Log frequency across categories $(F(3,76)=1.65, p=.18)$, and words were also equivalently matched on number of syllables and letters. As frequency data were unavailable for ANDROID ${ }^{4}$, the value used in the calculations for this entity was the mean Log frequency value calculated for other entities in the machines category.

Ten editors, proofreaders, and writers involved in English language publications were recruited via the snowballing method. It was assumed that as these professionals are highly fluent in the English language and are practiced in semantic assessment as part of their job, they would be suitable judges of whether the entities were representative of the respective categories.

The volunteers were asked to rate how representative each entity was of its category on a visual analogue scale (VAS), a 10-cm-long continuous line where the leftmost end indicates "not at all representative" and the rightmost end of the line, "very representative." From each category, the 10 most representative entities were selected, resulting in 40 entities in total (Appendix 1).

\section{Human Attribute Items}

The UH and HN attributes were chosen from Haslam's previous studies (Haslam \& Bain, 2007; Loughnan \& Haslam, 2007), and there were an equal number of attributes carrying positive and negative connotations. The humanness attributes along with their affective connotations are shown in Table 1. Of note, DISTANT was selected to replace COLD, which was the original stimulus used in Loughnan and Haslam (2007), as COLD can be interpreted in various ways and was considered to be ambiguous.

3 "The English Lexicon Project (supported by the National Science Foundation) affords access to a large set of lexical characteristics, along with behavioral data from visual lexical decision and naming studies of 40,481 words and 40,481 nonwords." http://elexicon.wustl.edu/

4 Data collection preceded the advent of the Google Android operating system in 2013. 
The attribute terms were matched on lexical characteristics such as length and Log frequency, using data from the ELP website (Balota et al., 2007). The same HN word was always paired with the same UH word (see Table 1), although the position of the word on the screen-whether it was presented above or below-was counterbalanced. Affect valence (i.e., positive/negative connotations) was not considered in analyses or discussion, because it was included as a control feature only to ensure that neither HN nor UH attributes were skewed in either direction connotatively.

\section{Apparatus}

The attribution task was generated via the computer program E-Prime Version 2.1 (2008) and run using the associated program, E-Run, which provides millisecond accuracy in timing. Both these programs were installed on a laptop, which was used to collect experimental data; responses were recorded via pressing designated keys on the keyboard. All other programs (including screensavers) were deactivated so as to minimize lag and ensure that the response times recorded were accurate.

\section{Design}

The 40 entities ( 10 in each of the 4 categories) were each presented 12 timesonce for each of the six $\mathrm{UH} / \mathrm{HN}$ attribute pairs with WHO, and once for each of the six attribute pairs with TнAт. This resulted in a full set of 480 experimental item sets.

TABLE $1 \quad H N$ and UH human attribute item Pairs matched on lexical characteristics

Human attribute trait types

\begin{tabular}{lll}
\cline { 2 - 2 } Affect valence & Human Nature $(\mathrm{HN})$ & Uniquely Human $(\mathrm{UH})$ \\
\hline Positive & CURIOUS & ORGANIZED \\
& FRIENDLY & HUMBLE \\
TRUSTING & POLITE \\
\cline { 2 - 2 } Negative & JEALOUS & \\
& AGgRESSIVE & SHALLOW \\
& NERVOUS & RUDE \\
& DISTANT
\end{tabular}


The attribution task thus consisted of 480 trials, with an additional 12 practice trials prior to the experimental trials to allow participants to familiarize themselves with the experiment. The trials were split into two blocks (block A, block B) of 240 trials each, and the blocks were counterbalanced-half of the participants were presented with the blocks in A-B order, and the other half in B-A order. Within each block, the trials were randomized.

All instructions and text were shown in white font on a black background, the only exception being the "No response detected" screen, which was shown in red font on a black background.

\section{Questionnaire}

A questionnaire administered after the experiment collected demographic data (e.g., age and gender) and assessed participants' basic grammatical knowledge in a short grammaticality test comprising 10 questions checking if participants knew how to properly use WHO and THAT (modeled after Jacobs, 2005), and a section to ascertain that participants understood the meaning of the humanness items. For the latter, they were to put a checkmark next to the attribute words that they understood.

The 10 questions were based on simple statements used in English language classes to test understanding of basic rules of grammar. Participants were to select the word (either wно or тнат) best suited to fill in the blank in the sentence. An example of one of the grammaticality test items is "Yesterday I saw a lawyer was really old."

\section{Participants}

Eighty-three participants took part in the experiment. All participants were Psychology students from James Cook University (Singapore campus), recruited via an advertisement posted on the research recruitment notice board. All participants had English as their first language, and normal or corrected-fornormal vision. Respondents received partial course credit for participating, although four participants were not eligible for credit and received no incentive.

The majority of the participants were female $(78 \%)$, with 18 males $(22 \%)$ in the sample, and participant age ranged from 18 to 40 years $(M=22.47$ years, $S D=4.61$ years). The sample consisted primarily of students of Chinese ethnicity $(63 \%)$, and $24 \%$ of the sample was of Indian ethnicity. The rest of the sample were either from other ethnic groups (e.g., Malay, Caucasian) or of mixed ethnicity (e.g., Chinese-Indian).

Participants generally exhibited a good grasp of basic grammar; the majority $(81 \%)$ obtained a perfect score on the grammaticality test, and the lowest score on the test was 7 out of 10 (one participant). Most participants indicated 
that they understood all 12 human attribute words (95\%), with 9 being the lowest number of words understood.

\section{Procedure}

Participants completed the task individually and independently. As part of the verbal briefing before the task, participants were warned that although the trials would seem repetitive, it was very important that they continually use the same decision-making process throughout the experiment; that is to say, they had to choose the most suitable attribute of the two presented after the probe phrase for every trial. Additionally, they were cautioned that they had to respond within a certain amount of time, after which they would see a screen displaying the phrase "No response detected." They were told that if this screen appeared, they should respond more quickly afterward.

For each trial, participants were presented with a fixation cross in the middle of the screen for $500 \mathrm{~ms}$ to focus their attention on the center of the screen, followed by the probe phrase (e.g., "monkeys who are") for 2,00o ms, then the $\mathrm{UH} / \mathrm{HN}$ pair words for 2,000 ms. The sequence either ended with a response from the participant selecting one of the two attributes on screen, or the sequence timed out after 2,000 ms and the "No response detected" screen was displayed. The inter-stimulus interval was set at $500 \mathrm{~ms}$.

\section{Results}

\section{Analysis of Data}

For all participants, response times faster than $500 \mathrm{~ms}$ were replaced with blank responses. Missing data, recorded in E-Run as o ms, were also replaced with blank cells. Data collected from 15 participants were excluded, as more than $25 \%$ of their overall data were blank and it was suspected that participants had been responding as rapidly as possible as a strategy to move through items quickly. In addition, data from three participants were lost due to corruption of files or computer program errors.

After all exclusions and losses of data, 65 data sets were analyzed using SPSs, with the alpha level set to .05 for all analyses. A repeated measures 2 (Humanness: HN, UH $) \times 2$ (Pronoun: WHO, THAT $) \times 4$ (Entity category: animals, named animals, machines, people) ANOVA was run. Partial eta squared is reported throughout $\left(\eta_{\mathrm{p}}{ }^{2}\right)$. According to Cohen's (1988) recommendations, $\eta_{\mathrm{p}}{ }^{2}$ values below .01 are considered small, .06 as moderate, and .14 and above as large.

Across all analyses, skewness and kurtosis statistics fell in the +2 to2 range; hence, the assumption of normality was not violated. The assumption 
of homogeneity of variance was violated when data were analyzed across categories. However, ANOVA is generally robust even when assumptions are violated (Howell, 2002), so we proceeded with parametric analyses. Mean response times across all conditions are displayed in Table 2. Mean response times for individual items across HN-primary and UH-primary pairs are presented in Appendix 1a-b.

\section{Main and Interaction Effects}

A main effect for humanness was found, $F(1,64)=4.64, p=.035, \eta_{p}^{2}=.068$. However, even though the difference is statistically significant and the effect size is moderate, in practical terms response times to $\mathrm{HN}$ items and to $\mathrm{UH}$ items differ very little, by only about $6 \mathrm{~ms}$ (Figure 1).

A main effect for pronoun was absent, $F(1,64)=.98, p=.326, \eta_{\mathrm{p}}{ }^{2}=.015$, but a significant main effect for entity category was observed, $F(3,62)=4.33, p=$ $.008, \eta_{\mathrm{p}}{ }^{2}=.173$, indicating that participants responded differently to stimuli from the four entity categories. Regardless of pronoun, the fastest response times were for the named animal category, followed by the animal category, the people category, and the machine category (Figure 2).

An interaction between pronoun and entity category was found to be statistically significant, $F(3,62)=3.17, p=.03, \eta_{\mathrm{p}}{ }^{2}=.133$. Given an initial expectation that the effect of pronoun use would be subtle, this interaction is reassuring. The interaction between entity categories and pronouns is shown in Figure 3 .

TABLE 2 Mean response times in milliseconds (and standard deviations) for items across all conditions (humanness, pronoun, entity category)

\begin{tabular}{lllll}
\hline \multirow{2}{*}{ Entity categories } & \multicolumn{3}{c}{ Human nature } & \multicolumn{2}{c}{ Uniquely human } \\
\cline { 2 - 5 } & That & Who & That & Who \\
\hline Animals & 1,055 & 1,047 & 1,066 & 1,068 \\
& $(43.84)$ & $(52.92)$ & $(52.33)$ & $(49.72)$ \\
Named animals & 1,066 & 1,076 & 1,085 & 1,078 \\
& $(40.44)$ & $(48.42)$ & $(49.22)$ & $(39.19)$ \\
Machines & 1,046 & 1,055 & 1,053 & 1,056 \\
& $(39.88)$ & $(45.55)$ & $(40.19)$ & $(35.22)$ \\
People & 1,081 & 1,065 & 1,079 & 1,059 \\
& $(34.31)$ & $(46.60)$ & $(45.20)$ & $(33.15)$ \\
\hline
\end{tabular}


To test the for simple main effects of pronoun, four paired-samples $t$ tests (two-tail) were performed to test the difference between mean response times to priming phrases including THAT and WHO across each of the four entity categories. The values used in the calculations were average response times collapsed across the two humanness conditions, and a new alpha of .0125 was applied using the Bonferroni correction for familywise error in multiple comparisons. No significant difference was found for entity categories of animals, $t\left(5^{8}\right)=0.33, p=.74$, named animals, $t\left(5^{8}\right)=-0.81, p=.42$, or machines, $t\left(5^{8}\right)=$ $-0.16, p=.87$. There was a significant difference in mean response times for trait attributions when paired with either THAT or WHO when it came to people, $t$ $(58)=2.69, p=.01$. Participants responded more slowly when trait attributes were paired with the relatively incongruent THAT (e.g., "Farmers that are friendly") than when paired with wHo.

The three-way interaction among humanness, pronoun and category was not significant, $F(3,62)=.81, p=.491, \eta_{\mathrm{p}}{ }^{2}=.038$. The lack of a statistically significant interaction among the three variables means the main hypothesis of the study was not supported.

\section{Discussion}

The main hypothesis - that attributions of humanness to entities such as animals, named animals, machines, and people would be influenced by the use of

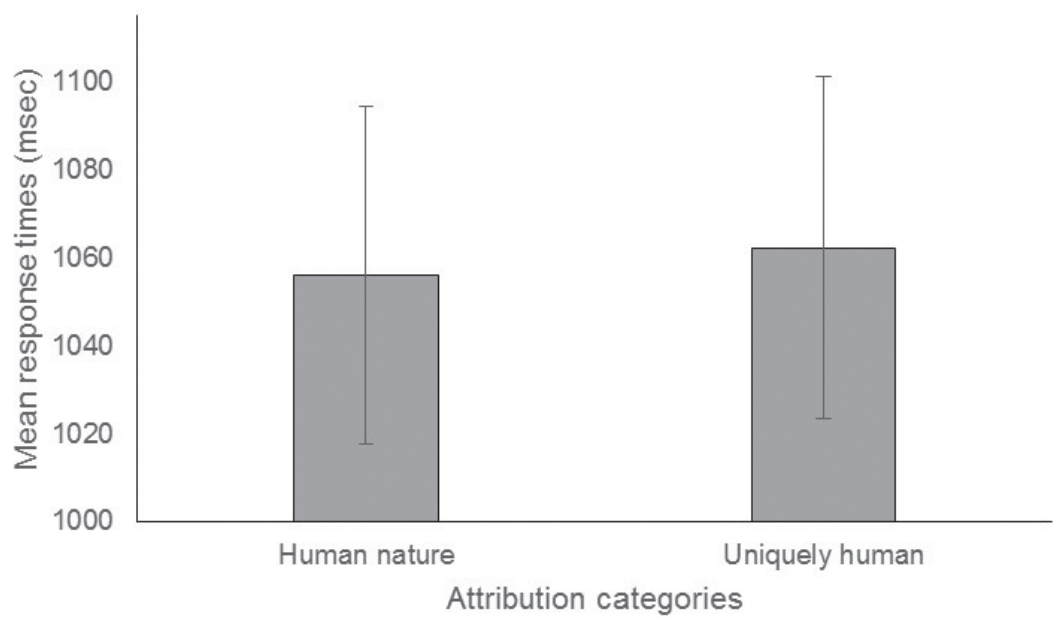

FIGURE 1 Mean response times in milliseconds to HN attribute words and UH attribute words. The error bars indicate $95 \%$ confidence intervals. 


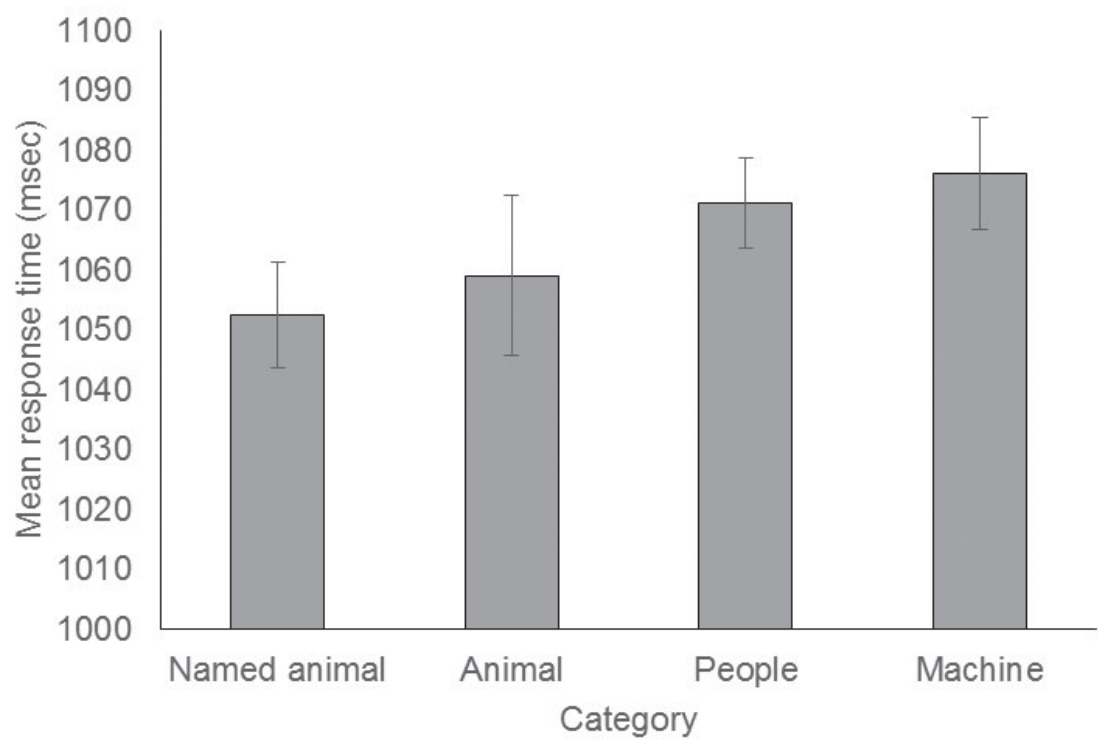

FIGURE 2 Mean response times in milliseconds to items from the four categories: animals, machines, named animals and people. Error bars indicate $95 \%$ confidence intervals.

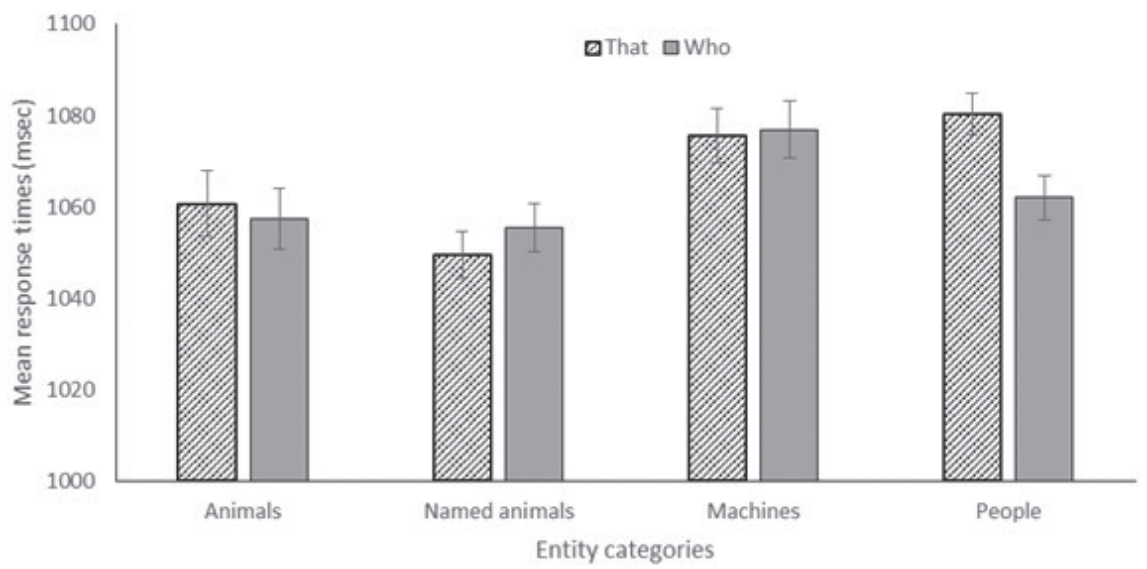

FIGURE 3 Interaction between entity category and pronoun, which was found to be significant across subjects and bordered significance across items. Error bars indicate standard error. 
either WHO or THAT in a priming phrase-was not supported by the data collected in this study. However, the results still present interesting information that adds to the literature.

A strong main effect for category (large effect size) was found, indicating that people responded differently according to the entities in the four categories. This makes logical sense, as one would expect participants to find some congruence with other humans relative to other entities. As for attributing humanness to the various types of entities, verbal feedback from participants indicated that most found it extremely odd to attribute human traits to machines in particular, and this is reflected in the relatively slower response times to machine items. However, the people category produced the second slowest response times and this was not anticipated; one would expect that response times to items in the people category would be fastest, as all $\mathrm{UH}$ and $\mathrm{HN}$ word choices are related to people but not all of them are related to the other categories.

A possible explanation for this might be that the humanness attribute words chosen for the study were incongruent with particular items in the people category, as certain professions are stereotypically linked to specific characteristic human traits (Loughnan \& Haslam, 2007). For example, journalists may be stereotyped as curious people and soldiers may be seen as aggressive, but aggression and curiosity may not fit into the stereotyped perceptions of journalists and soldiers, respectively. This incongruence may have resulted in relatively slower response times on particular items, thereby affecting the overall category mean. Further study regarding attributions of humanness across various professions may be of assistance in explaining the results of the current study.

The observed main effect for humanness, with significantly slower responses when uniquely human trait attributes were used as primes compared with human nature trait attributes provides partial support for Haslam's concept of humanness (Haslam, 2006). That responses to HN and UH attribute items differed in a statistically significant manner provides support for the idea that $\mathrm{UH}$ and $\mathrm{HN}$ traits each collectively convey psychologically different meanings. While in practical terms the difference of $6 \mathrm{~ms}$ appears minimal, the effect size is moderate and indicates that further exploration could be fruitful.

The interaction between pronoun and category was statistically significant. Nevertheless, the $t$-test analyses revealed that the significant interaction was due to the pronoun difference for items in the people category with slower mean response times for primes including THAT than wHO. From a grammatical viewpoint, the results make sense, as wHO should be the most appropriate referent to people items relative to other entities, resulting in easier, faster processing and so the briefest response times. Since Loughnan and Haslam (2007) already found artists to be associated with $\mathrm{HN}$ traits and businesspeople to be associated with UH traits, a possible avenue of study may involve the 
investigation of how WHO and THAT may influence the attribution of humanness to artists and businesspeople. By focusing on these two specific examples about which information is already available, the research may help to clarify the results of the current study.

Aside from statistical results, several noteworthy observations were also generated from the experiment. Firstly, not many participants voluntarily mentioned the WHо/тнAт discrepancy in the 480 experimental items. Of those who did, the most common complaint was that the probe phrases were referentially incorrect (e.g., "printers who are ..."). However, when the wHo/ THAT discrepancy was pointed out, most acknowledged that they had noticed some items featured wHO and others featured тнат. Incongruous combinations were most often noticed and remembered, and machine items with wHO were noted as the most distinctive (e.g., "treadmills who are ..."). A few participants also said they had not noticed the wHо/THAT variations at all.

Although the main hypothesis was not supported, it may be premature to conclude that WHO and THAT primes did not have an effect on attributions of humanness across various types of human and nonhuman entities. It could be that the phenomenon is so subtle that the current experimental design did not register it; as mentioned previously, even though statistically significant differences were found, in reality these differences in response time were very small. This is not to say that the current design was ineffective; in general, statistical power was found to be good and the overall design was strong (e.g., within-subjects design, ample representation per category, sufficient repetitions). However, to find the most appropriate methodology, future research could compare the efficacy of the attribution task used here with other suitable methods such as a lexical decision task.

Of course, we must also consider the limits to ecological validity intrinsic to experimental designs. Neither the study reported here nor any proposed experimental studies could properly capture the lived experience of people's daily encounters with and deployment of language, intentional or otherwise. This is not to say experimental studies such as this one are not valuable in being able to capture measurable responses to nuances of difference in linguistic constructions - they certainly can. However, corpus analyses via searches through Google or other large corpora such as those employed by Gupta (2006) and Jacobs (2005) have their own limitations in the onus of having to read through large quantities of text to locate patterns. Gupta acknowledged the need to "reduce the number of hits to a figure that is small enough for me to read and large enough for me to see some patterns" (p. 111).

What might be considered another limitation of the study is that the limited participant sample does not allow us to examine potential cultural variation. However, given that this is a novel attempt to address a previously untested 
research question, it cannot be expected that we could control for potential cultural variation in the representations of nonhuman animals (or machines for that matter). The aforementioned corpus analysis methodology might also be better suited to determine cultural variations so that these are more clearly identified, prior to any attempt to incorporate these as a factor in an experimental design.

\section{Conclusion}

As concerns the current study, another possible explanation for the non-significant results obtained for the three-way interaction is that wHO may be no longer closely linked to humanness and therefore nullifying the response congruency effect in this context. In terms of rhetorical strategies employed in both human and nonhuman animal advocacy, the current study findings offer the insight that people seem to have no unconscious leaning towards perceiving nonhuman animals as only things in that there was no obvious response congruency effect between THAT or WHO for entities in the animal and named animal categories. Gupta's finding that fox hunters readily referred to foxes as WHO is perhaps not so much an overt exploitation of language to justify violence but rather an unconscious shifting of foxes along the humanness continuum through acknowledging their human nature characteristics. The response congruency effect was evident for the people category such that participants appeared to find some incongruence when people were referred to as THAT (e.g. "musicians that are ..."), which perhaps reduces the notion of beingness. Unfortunately, this neither explains the relatively common use of THAT in reference to people in everyday communication nor provides any further insight into the theorized humanness continuum with respect to people.

Gilquin and Jacobs (2006) and Gupta (2006) both found that wHO is no longer solely used to refer to humans. In particular, Gilquin and Jacobs (2006) examined the use of wHo with nonhuman animals over the past 40 years, indicating that language changes are likely to be gradual such that most people may not notice. Considering how widespread is the generalized use of TнAT in reference to humans (e.g., in novels such as the still-popular The Catcher in the Rye, and in current newspaper articles), it could be that any previously strong link between wHO and humanness is fading, as people begin to replace the relative pronoun WHO with тнAT. In short, it is possible that WHO is gradually being replaced by тнAт, to the extent that it no longer carries humanizing, phenomenological connotations of being. There is scope for further text analysis studies tracking the use of WHO and THAT in relation to humanness attributes or dehumanizing words (respectively) to properly document this hypothetical shift in language use. 


\section{Acknowledgments}

The authors are sincerely grateful to Dr. George Jacobs and the three independent reviewers who provided editorial advice and insightful comments on drafts of the manuscript.

\section{References}

Arendt, H. (1951). The decline of the nation-state and the end of the rights of man. In The Origins of Totalitarianism. Retrieved 15 February, 2017, from http://www.cscd .osaka-u.ac.jp/user/rosaldo/15Decline_nation-state.html

Balota, D. A., Yap, M. J., Cortese, M. J., ... Treiman, R. (2007). The English lexicon project. Behavior Research Methods, 39(3), 445-459.

Barrett, J. (2009, December 27). Remembering the children that are still missing [Web log message]. Blogger News Network: High-quality English language analysis and editorial writing on the news. Retrieved January 23, 2017, from http://www.bloggernews .net/123377

Brook, B. (2016, February 11). Experts warn of triggers that can turn kids into killers in the wake of an 11-year-old charged with murder. Lifestyle: Real Life True Stories. Retrieved January 23, 2017, from http://news.com.au

Brooks, L. (1983). Sexist language in occupational information: Does it make a difference? Journal of Vocational Behavior, 23(2), 227-232.

Brown, R. (1958). Words and Things. Glencoe, IL: The Free Press.

Cambridge Dictionaries Online. (2016). Retrieved April 23, 2016, from http://dictionary .cambridge.org/dictionary/english/who

Carroll, J. B. (Ed.). (1956). Language, thought, and reality: Selected writings of Benjamin Lee Whorf. Cambridge, MA: MIT Press.

Chartrand, T. L., Fitzsimons, G. M., \& Fitzsimons, G. J. (2008). Automatic effects of anthropomorphized objects on behavior. Social Cognition, 26(2), 198-209.

Children that are secondhand smokers could have extended sleep problems. (2010, January 24). UK Health Centre. Retrieved from http://www.healthcentre.org.uk/ sleep-disorders/news.html

Chung, C., \& Pennebaker, J. (2007). The psychological functions of function words. In K. Fiedler (Ed.), Social communication (pp. 343-359). New York, NY: Psychology Press.

Dunayer, J. (2001). Animal equality: Language and liberation. Derwood, MD: Ryce Publishing. 
Gilquin, G., \& Jacobs, G. M. (2006). Elephants who marry mice are very unusual: The use of the relative pronoun who with nonhuman animals. Society \& Animals, 14(1), 79-105.

Gupta, A. F. (2006). Foxes, hounds, and horses: Who or which? Society \& Animals, 14(1), 107-126.

Hart, W., \& Albarracín, D. (2009). What I was doing versus what I did: Verb aspect influences memory and future actions. Psychological Science, 2o(2), 238-244.

Haslam, N. (2006). Dehumanisation: An integrative review. Personality and Social Psychology Review, 10(3), 252-264.

Haslam, N., \& Bain, P. (2007). Humanising the self: Moderators of the attribution of lesser humanness to others. Personality and Social Psychology Bulletin, 33(1), 57-68.

Haslam, N., Bain, P., Douge, L., Lee, M., \& Bastian, B. (2005). More human than you: Attributing humanness to self and others. Journal of Personality and Social Psychology, 89(6), 937-950.

Hawthorne, N. (1997). The Scarlet Letter. Retrieved January 20, 2010, from http://www .gutenberg.org/dirs/etext92/scrlt13.txt (Original work published 1850).

Hussain, Z. (2010, January 24). Lauded for role in Johor's growth. The Sunday Times, p. 2. Jacobs, G. (2005). Extending the circle of compassion to include nonhuman animals: the case of the use of who as seen in grammars and dictionaries. Language and Ecology, 1(4). Retrieved April 11, 2008, from http://www.ecoling.net/journal.html

Khanna, R. (2008). Indignity. Positions: East Asia Cultures Critique 16(1), 39-77.

Kwan, V. S. Y., \& Fiske, S. T. (2008). Missing links from social cognition: The continuum from nonhuman agents to dehumanised humans. Social Cognition, 26(2), 125-128.

Loughnan, S., \& Haslam, N. (2007). Animals and androids: Implicit associations between social categories and nonhumans. Psychological Science, 18(2), 116-121.

McNamara, T. P. (2005). Semantic Priming: Perspectives from Memory and Word Recognition. New York, NY: Psychology Press.

Pennebaker, J. W. (2002). What our words can say about us: Toward a broader language psychology. Psychological Science Agenda, 15(1), 8-9.

Pennebaker, J. W., \& King, L. A. (1999). Linguistic styles: Language use as an individual difference. Journal of Personality and Social Psychology, 77(6), 1296-1312.

Pennebaker, J. W., Mehl, M. R., \& Niederhoffer, K. G. (2003). Psychological aspects of natural language use: Our words, our selves. Annual Review of Psychology, 54, 547-577. Ruskin, J. (1856). Of the pathetic fallacy. In Modern Painters, volume 3, part 4. Retrieved February 15, 2017, from http://www.ourcivilisation.com/smartboard/shop/ruskinj/ Salinger, J. D. (1984). The Catcher in the Rye. Harmondsworth, United Kingdom: Penguin in association with Hamilton. (Original work published 1951).

Zipf, G. K. (1935). The Psychobiology of Language. Boston, MA: Houghton Mifflin. 


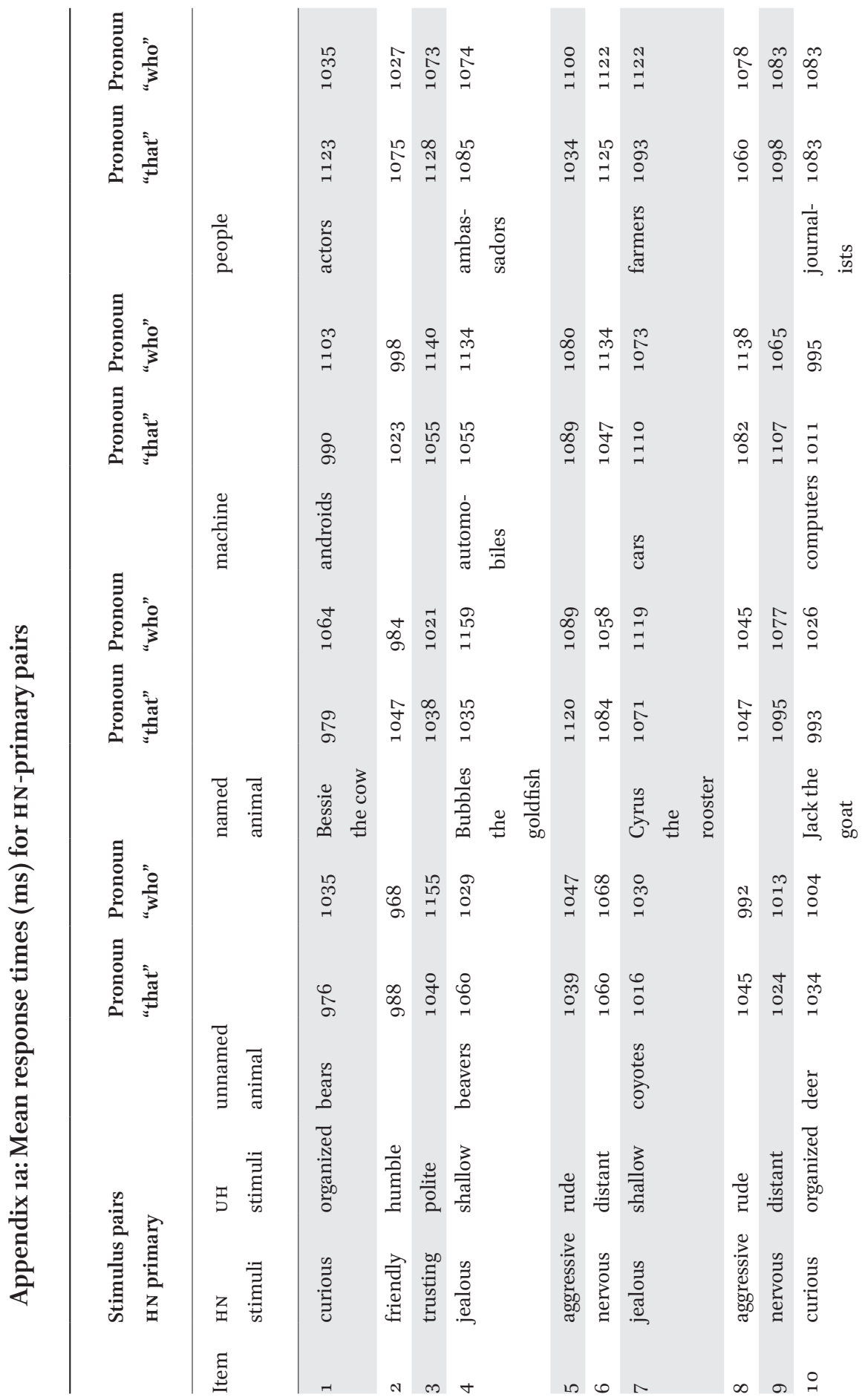




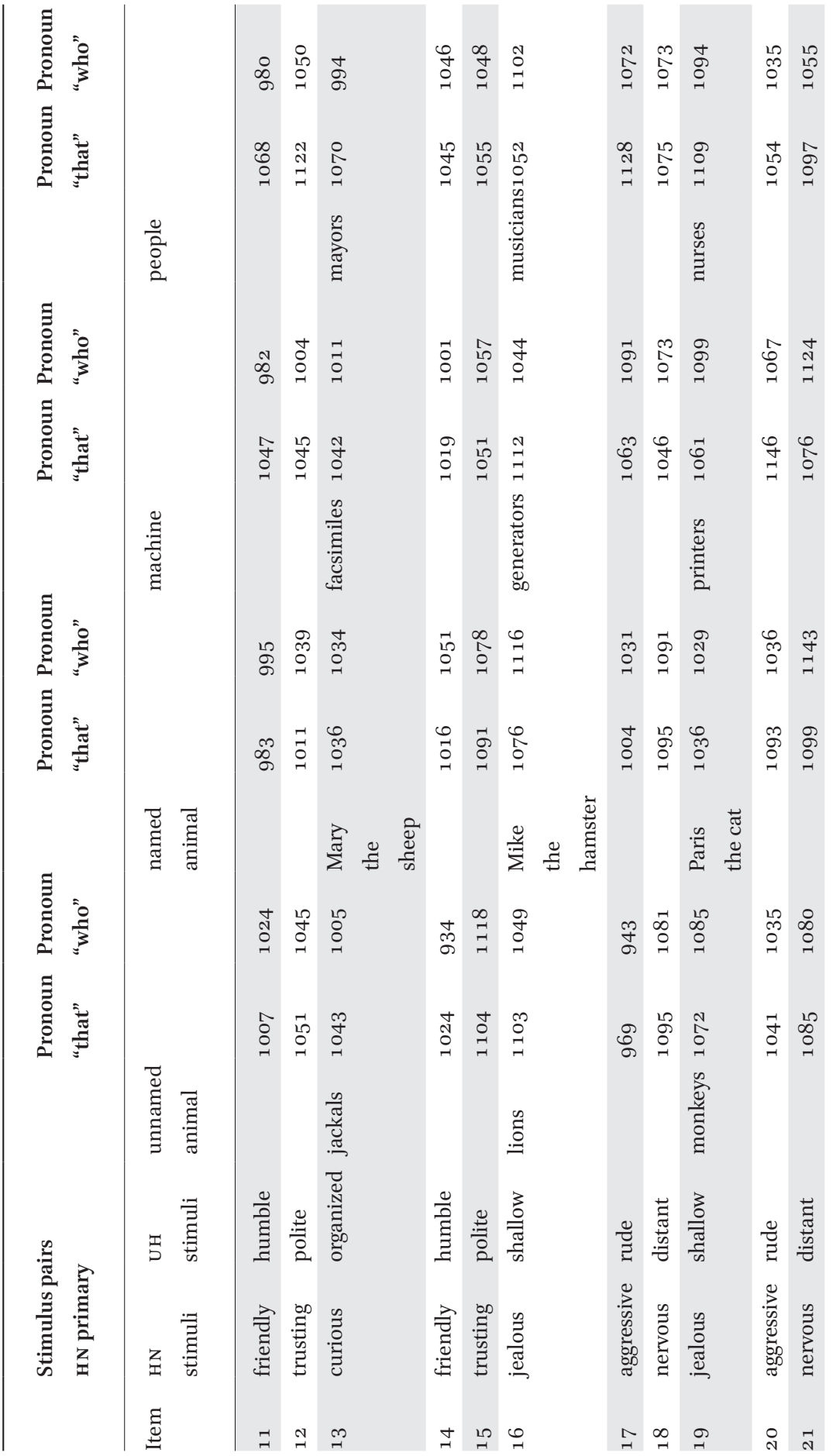




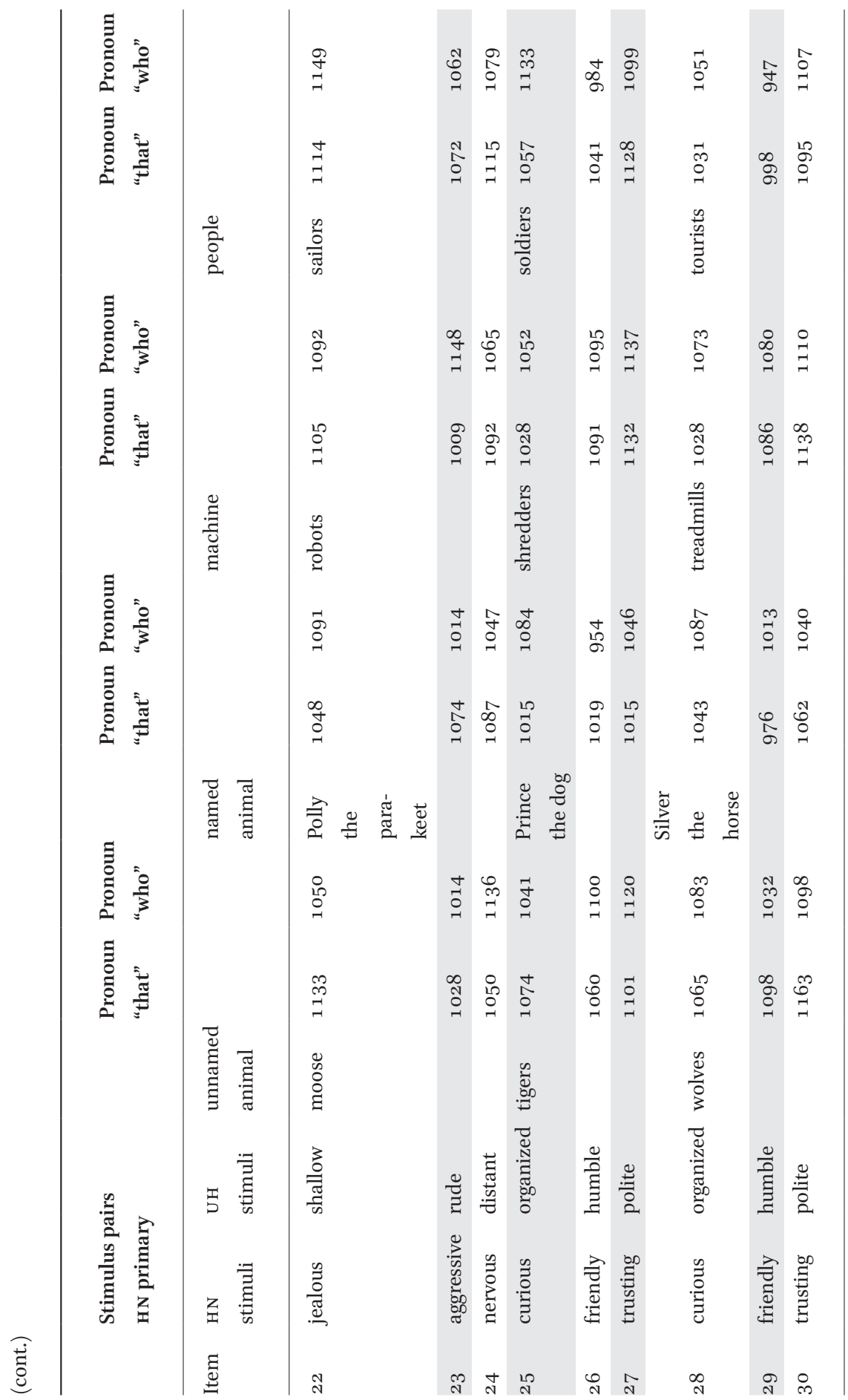




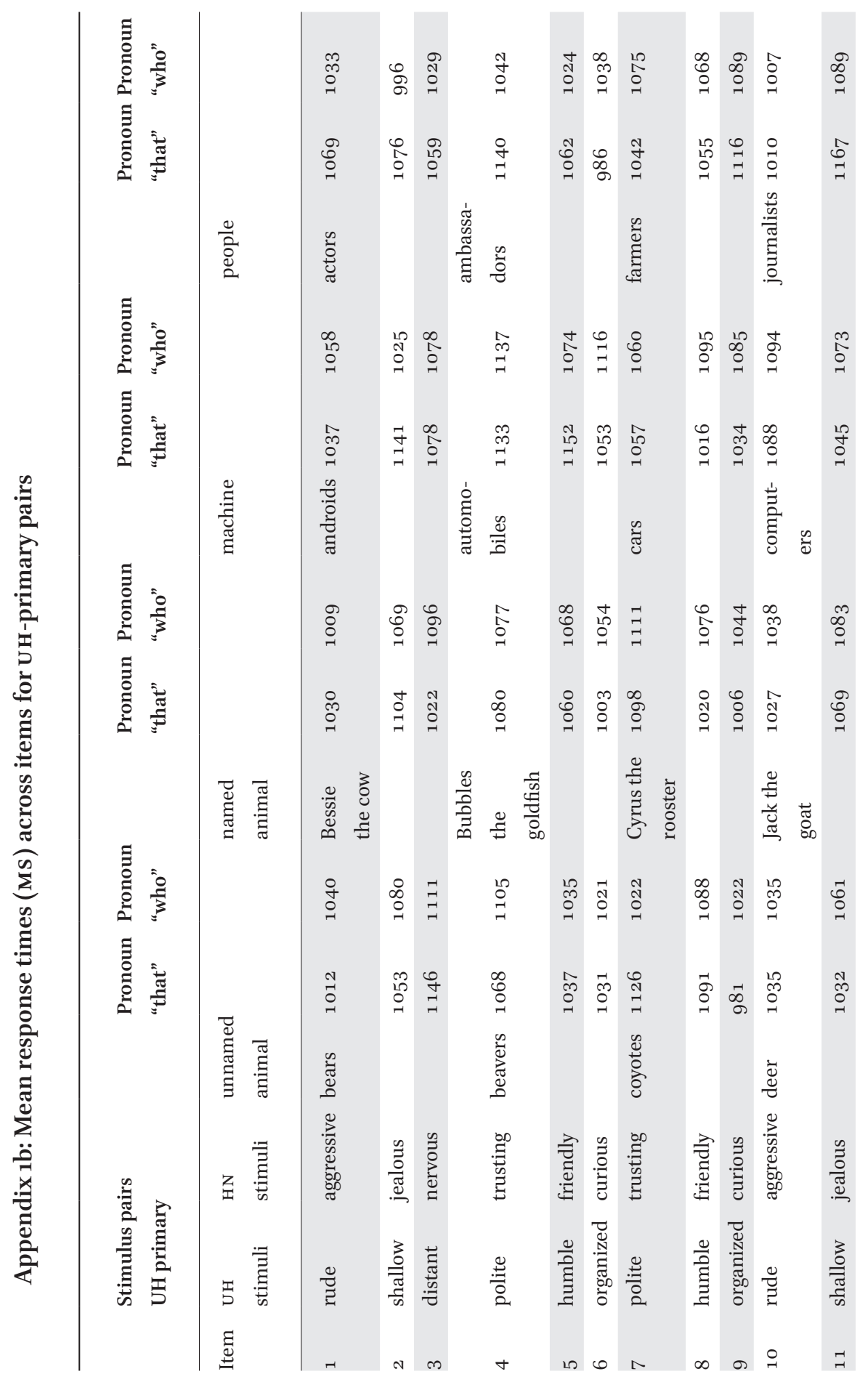




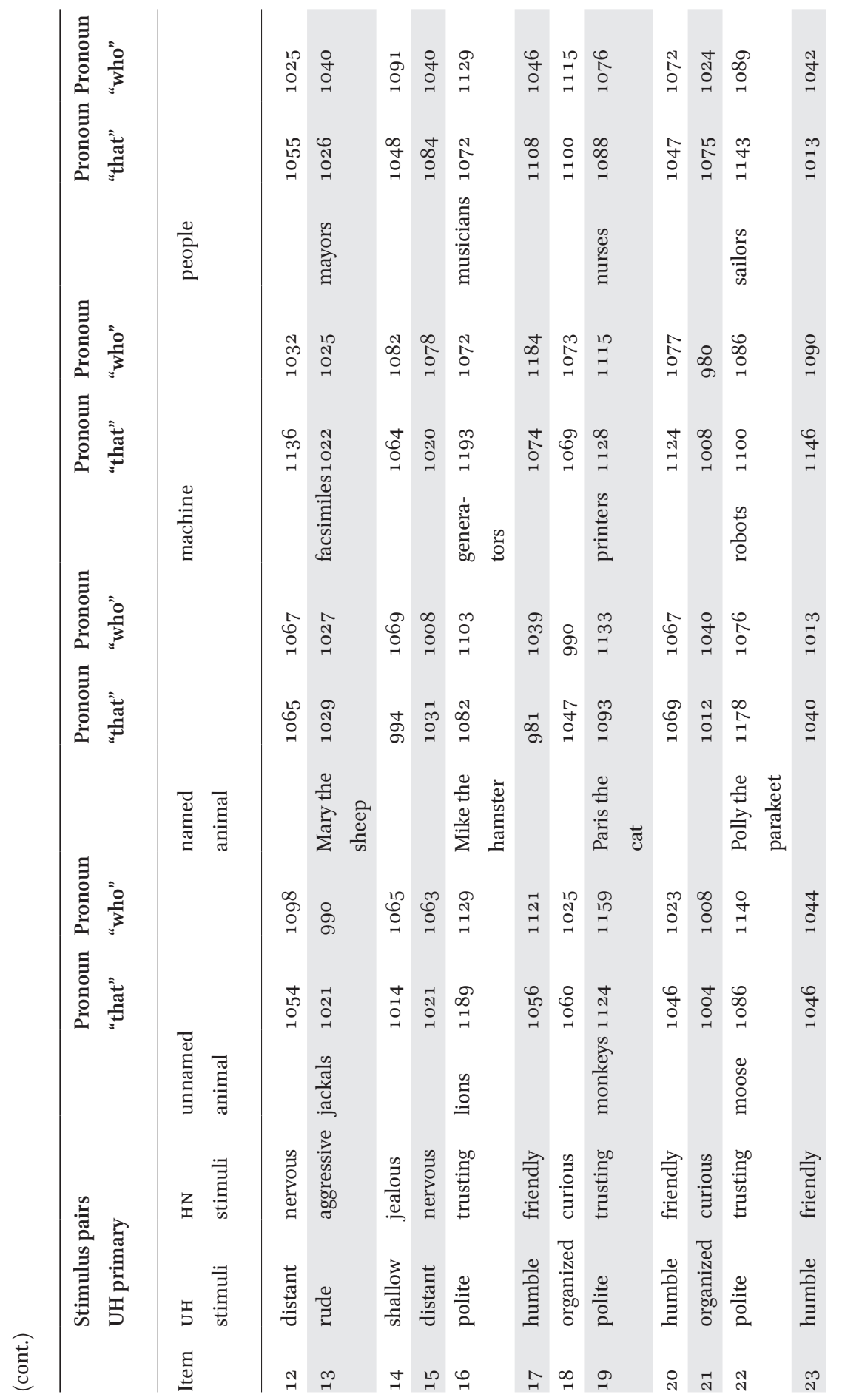




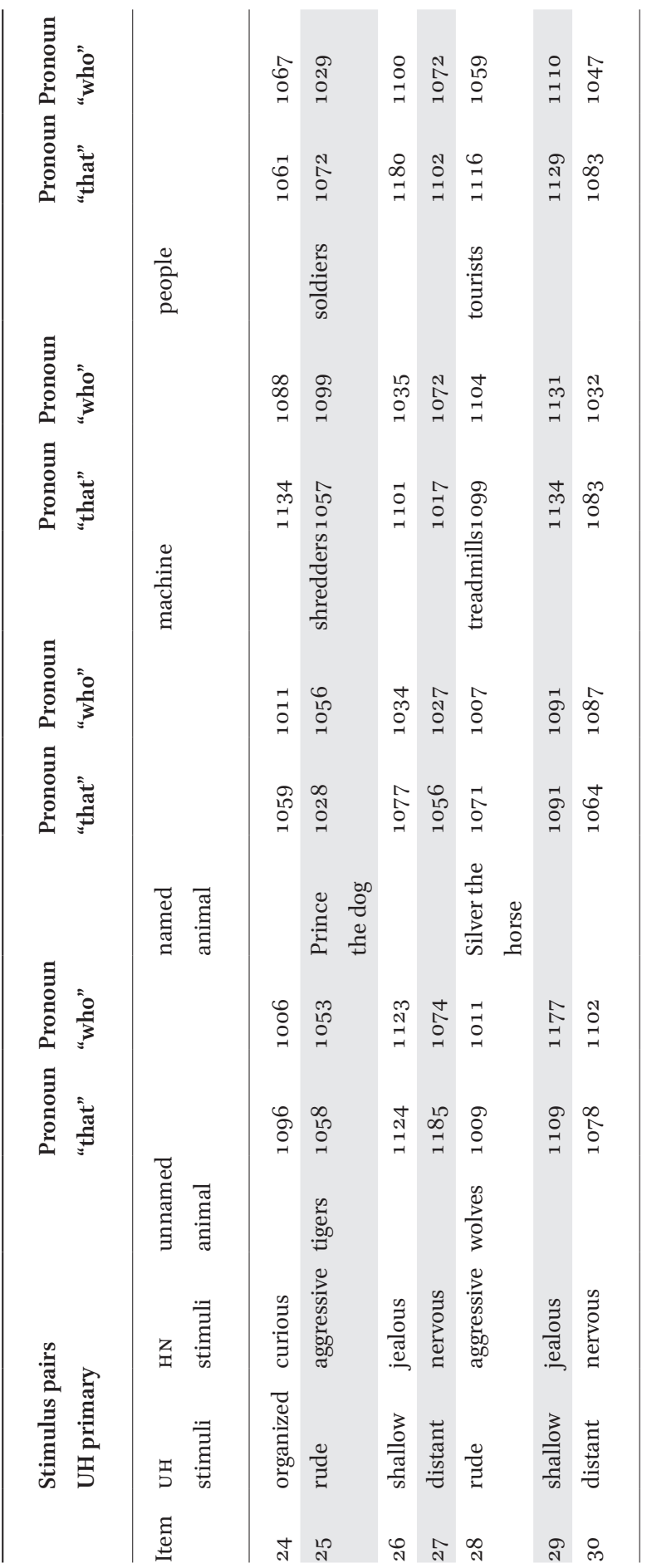

